\title{
Cryptotanshinone has curative dual anti-proliferative and immunotherapeutic effects on mouse Lewis lung carcinoma
}

\author{
Shuo Liu ${ }^{1,2} \cdot$ Zhen Han $^{1} \cdot$ Anna L. Trivett ${ }^{1} \cdot$ Hongsheng Lin $^{2} \cdot$ Sean Hannifin ${ }^{1} \cdot$ De Yang ${ }^{1} \cdot$ Joost J. Oppenheim $^{1}$ (1)
}

Received: 27 March 2018 / Accepted: 19 March 2019 / Published online: 10 April 2019

(c) The Author(s) 2019

\begin{abstract}
Lung cancer is currently the leading cause of cancer-related mortality with very limited effective therapy. Screening of a variety of traditional Chinese medicines (TCMs) for their capacity to inhibit the proliferation of human lung cancer A549 cells and to induce the in vitro maturation of human DCs led to the identification of cryptotanshinone (CT), a compound purified from the TCM Salvia miltiorrhiza Bunge. Here, CT was shown to inhibit the proliferation of mouse Lewis lung carcinoma (LLC) cells by upregulating p53, downregulating cyclin B1 and Cdc2, and, consequently, inducing G2/M cell-cycle arrest of LLC cells. In addition, CT promoted maturation of mouse and human DCs with upregulation of costimulatory and MHC molecules and stimulated DCs to produce TNF $\alpha$, IL- $1 \beta$, and IL-12p70, but not IL-10 in vitro. CT-induced maturation of DCs depended on MyD88 and also involved the activation of NF- $\mathrm{kB}$, p38, and JNK. CT was effective in the treatment of LLC tumors and, when used in combination with low doses of anti-PD-L1, cured LLC-bearing mice with the induction of subsequent anti-LLC long-term specific immunity. CT treatment promoted T-cell infiltration and elevated the expression of genes typical of Th1 polarization in LLC tumor tissue. The therapeutic effect of CT and low doses of anti-PD-L1 was reduced by depletion of CD4 and CD8 T cells. This paper provides the first report that CT induces immunological antitumor activities and may provide a new promising antitumor immunotherapeutic.
\end{abstract}

Keywords Cryptotanshinone $\cdot$ Lewis lung carcinoma $\cdot$ Dendritic cells $\cdot$ Cancer therapeutic $\cdot$ Cell-cycle arrest

$\begin{array}{ll}\text { Abbreviations } \\ \mathrm{CT} & \text { Cryptotanshinone } \\ \mathrm{Cdk} & \text { Cyclin-dependent protein kinase } \\ \mathrm{Cdc} 2 & \text { Cyclin-dependent protein kinase } 2 \\ \mathrm{CTL} & \text { Cytotoxic T lymphocyte }\end{array}$

Shuo Liu and Zhen Han have contributed equally to this study.

Electronic supplementary material The online version of this article (https://doi.org/10.1007/s00262-019-02326-8) contains supplementary material, which is available to authorized users.

De Yang

yangd@mail.nih.gov

$\triangle$ Joost J. Oppenheim

oppenhej@mail.nih.gov

1 Cancer and Inflammation Program, Center for Cancer Research, National Cancer Institute, Frederick National Laboratory for Cancer Research (FNLCR), Rm 21-89/31-19, Bldg 560, 1050 Boyles Street, Frederick, MD 21702-1201, USA

2 Guang An Men Hospital of China Academy of Chinese Medical Sciences, Beijing, China

$\begin{array}{ll}\text { Erk } & \text { Extracellular signal-regulated kinase } \\ \text { JNK } & \text { c-Jun N-terminal kinase } \\ \text { LLC } & \text { Lewis lung carcinoma } \\ \text { M } \phi & \text { Macrophage } \\ \text { MAPK } & \text { Mitogen-activated protein kinase } \\ \text { PD1/PD-L1 } & \text { Programmed cell death protein 1/pro- } \\ & \text { grammed death ligand 1 } \\ \text { PI } & \text { Propidium iodide } \\ \text { TCM } & \text { Traditional Chinese medicine } \\ \text { WT } & \text { Wild-type }\end{array}$

\section{Introduction}

Lung cancer is the leading cause of cancer-related mortality worldwide, with a 5-year overall survival rate of only $15 \%$ for all stages of patients [1]. The majority $(\sim 75 \%)$ of lung cancer patients are diagnosed at an advanced stage of the disease [1-3]. Nonspecific cytotoxic chemotherapy is associated with severe side effects, while surgery is not effective for late-stage disease [3]. Targeted therapy against epidermal growth factor (e.g., erlotinib, afatinib, etc.) or anaplastic 
lymphoma kinase (crizotinib and ceritinib) is helpful only for a small subgroup of patients with relevant targetable genomic alterations [2]. Recently, checkpoint inhibitor antibodies against PD1 (Nivolumab and Pembrolizumab) or PD-L1 (Duvalumab, Atezolizumab, and Avelumab) have been used to treat lung cancer patients with an overall response rate of approximately $20-25 \%$ [3]. Therefore, the development of additional effective therapies for lung cancers is still needed.

Vertebrates generate specific immune responses against malignant tumor cells such as the production of IFN $\gamma$ and tumor-specific cytotoxic CD8 T cells [4, 5]. At advanced stages of cancers, including lung cancer, the tumor tissues become highly immunosuppressive due to the infiltration by immunoinhibitory cells such as Tregs and MDSCs and/ or the generation of inhibitory factors such as PD-1/PD-L1, lymphocyte activation gene-3, IL-10, and TGF $\beta$ [5-8]. The immunosuppressive tumor microenvironment yields at least two dire immunological consequences. One is to nullify the cancer cell-killing capacity of preexisting CTLs, which can be countered by checkpoint inhibitor antibodies [9]. The other is to incapacitate antigen-presenting DCs in the tumor tissue by preventing DC maturation and presentation of tumor-associated antigens to naïve $\mathrm{T}$ cells in the secondary lymphoid organs, thus, hampering the generation of additional tumor-specific CTLs [10-12].

Increased cancer cell number and tumor size play an essential role in cancer immunosuppression by producing many immunosuppressive factors such as $\operatorname{TGF} \beta[8,13]$, which then promotes IL-10 production and generation of Tregs and MDSCs [8, 13-15]. Therefore, reducing tumor burden would facilitate curtailing the immunosuppressive microenvironment in lung cancer. Another means of overcoming the immunosuppressive microenvironment would be to directly activate DCs in lung cancer tissues, so that they regain their antigen-presenting capacity and produce proinflammatory cytokines (such as TNF $\alpha$ and IL-12) capable of countering the immunosuppressive cytokines. Thus, any agent capable of simultaneously inhibiting the proliferation of lung cancer cells and inducing the maturation of DCs would be highly desirable.

TCMs are widely employed in China and some southeastern Asian countries for the treatment of cancers. The major theoretical principle for treating cancers in TCM is 'Gu Ben Qing Yuan', which in English grossly means 'simultaneously reinforcing the body's protective anticancer immune response and eliminating cancer cells. We speculated that certain TCMs might possess these dual capacities. We, therefore, screened more than a dozen of TCMs and purified TCM compounds that are used for the treatment of cancer patients. This led to the identification of cryptotanshinone (CT), a compound isolated from the TCM Danshen/Salvia miltiorrhiza Bunge [16], as an inhibitor of the proliferation of a human lung cancer cell line A549 and concomitant inducer of the maturation of human DCs. CT is biochemically well characterized [17], can be chemically synthesized [18], and is available commercially with more than $98 \%$ purity. We investigated the mechanistic basis by which CT inhibited the proliferation of lung cancer cells and stimulated the maturation of DCs. Furthermore, the capacity of CT to treat lung cancer was evaluated using the mouse Lewis lung carcinoma model. The data demonstrate that $\mathrm{CT}$ inhibited the proliferation of lung cancer cells, induced DC maturation via distinct signaling pathways, and had a curative effect on Lewis lung carcinoma in immunocompetent mice.

\section{Materials and methods}

\section{Reagents}

Compounds purified from various TCMs, including CT, were obtained from the National Institutes for Food and Drug Control (Beijing, China). CT was dissolved at a stock concentration of $15 \sim 20 \mathrm{mg} / \mathrm{ml}$ in DMSO and diluted into physiologic solutions or medium for experiments. LPS ( $E$. coli O55:B5) was from Sigma. Anti-PD-L1 (clone 10F.9G2) and control rat $\operatorname{IgG} 2 \mathrm{~b}$ (clone LTF-2) were purchased from BioXCell (West Labanon, NH).

\section{Proliferation assay}

A549 or LLC cells were seeded into a 96-well flat-bottomed tissue culture plate at $4 \times 10^{3} /$ well in appropriate medium and cultured in a $\mathrm{CO}_{2}$ incubator $\left(37^{\circ} \mathrm{C}\right.$ humidified aircontaining $5 \% \mathrm{CO}_{2}$ ) overnight. After adding $\mathrm{CT}$, the cells were incubated for $48 \mathrm{~h}$ and pulsed with tritiated thymidine $\left({ }^{3} \mathrm{H}-\mathrm{TdR}\right.$, New England Nuclear, North Billerica, MA) at $0.5 \mu \mathrm{Ci} /$ well for the last $4 \mathrm{~h}$. At the end of culture, the cells were collected onto a membrane with a 96-well harvester (INOTECH $_{\mathrm{AG}} \mathrm{IH}-280$, Dottikon, Switzerland) to measure ${ }^{3} \mathrm{H}-\mathrm{TdR}$ incorporation (CPM) using an automatic MicroBeta counter (Wallac). The change in the percentage (\%) of cell proliferation was calculated as: $\%$ Proliferation $=(\mathrm{CPM}$ with compound - CPM blank)/(CPM without compound - CPM blank) $\times 100$. The concentration at which $50 \%$ of the proliferation was inhibited $\left(\mathrm{IC}_{50}\right)$ was calculated using GraphPad Prism.

\section{DC generation and treatment}

Mouse dendritic cells (DCs) were generated by culturing mouse hematopoietic progenitors isolated from C57BL/6, $\mathrm{TLR}^{-/-}$, or MyD88 ${ }^{-/-}$mice as previously reported [19]. Mouse DCs at $5 \times 10^{5} / \mathrm{ml}$ in mGM-CSF-containing RPMI 1640 medium were cultured in a $\mathrm{CO} 2$ incubator with $\mathrm{CT}$ at 
indicated concentrations for specified time periods before harvesting culture supernatants and DCs for cytokine measurement and cytometric/signaling analysis, respectively.

\section{Detection of apoptosis}

LLC cells in a 12 -well plate $\left(3 \times 10^{5} / \mathrm{ml} /\right.$ well $)$ were cultured for $24 \mathrm{~h}$ with $\mathrm{CT}$ or $\mathrm{NaZ}_{3}$ (for positive control) at indicated concentrations. The cells were harvested by treating with $0.25 \%$ trypsin-2.21 mM EDTA, washed three times, and stained with an apoptosis detection kit (BMS500FI/300, eBioscience) consisting of FITC-conjugated annexin $\mathrm{V}$ and propidium iodide (PI) following the vendor's recommendation. The stained samples were assayed using an LSR II (BD) flow cytometer and analyzed using FlowJo.

\section{Cell-cycle analysis}

LLC cells with $70 \sim 80 \%$ confluency were washed and serum-starved in a $\mathrm{CO}_{2}$ incubator in DMEM medium containing $0.2 \%$ FBS for $48 \mathrm{~h}$ for synchronization. The synchronized LLC cells were plated into a 6 -well plate at $5 \times 10^{5} \%$ well in DMEM medium (10\% FBS) containing various concentrations of CT and cultured in a $\mathrm{CO} 2$ incubator for $24 \mathrm{~h}$. The resultant cells were washed twice with PBS and fixed in $70 \%$ ethanol for $30 \mathrm{~min}$ at $4{ }^{\circ} \mathrm{C}$. After fixation, the cells were washed twice with PBS and treated with $50 \mu \mathrm{l} /$ tube of $100 \mu \mathrm{g} / \mathrm{ml}$ of ribonuclease for $30 \mathrm{~min}$ at room temperature. Finally, $200 \mu \mathrm{l}$ of PI at $50 \mu \mathrm{g} / \mathrm{ml}$ was added into each tube and the cells were analyzed using an LSR II flow cytometer.

\section{Treatment of LLC for signaling analysis}

LLC cells were serum-starved in a $\mathrm{CO}_{2}$ incubator in DMEM medium containing $0.1 \%$ FBS overnight before they were treated with various concentrations of CT for $24 \mathrm{~h}$. The treated cells were solubilized in $1 \times$ SDS-PAGE sample buffer at $10^{7} / \mathrm{ml}$, boiled for $5 \mathrm{~min}$, and stored at $-20{ }^{\circ} \mathrm{C}$ until use.

\section{SDS-PAGE and western blot}

Samples and pre-stained standard separated on a 4-12\%

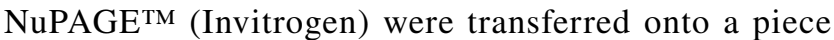
of Immobilon ${ }^{\mathrm{TM}}$ membrane (Millipore, Bedford, MA). The membranes were rinsed with TBS-T (TBS containing $0.05 \%$ Tween 20 ), blocked with $5 \%$ nonfat dry milk at room temperature for $1 \mathrm{~h}$, and incubated with appropriately diluted $(1: 500 \sim 2000) 1$ st antibodies overnight at $4{ }^{\circ} \mathrm{C}$. The first antibodies were rabbit IgG purchased from Cell Signaling (Beverly, MA), including anti$\mathrm{I}-\kappa \mathrm{B} \alpha$ (\#9242), anti-GAPDH (\#2118), anti-phosphop44/42 (\#9101, Thr202/Tyr204), anti-p44/42 (\#9102), anti-phosphorylated p38 (\#9211, Thr180/Tyr182), antip38 (\#9212), anti-phosphorylated JNK (\#9251, Thr183/ Tyr185), anti-JNK (\#9252), anti-phosphorylated p53 (\#9284, Ser15), anti-Cdc2 (\#77,055), and anti-cyclin B1 (\#4138). After washing three times with TBS-T, the membranes were reacted with 1:2000 diluted HRP-conjugated goat anti-rabbit IgG (Cell Signaling, \#70,741) for $1 \mathrm{~h}$ at room temperature, washed, and developed in SuperSignal ${ }^{\circledR}$ West Dura Extended Duration Substrate (Thermo Fisher Scientific Inc., Hanover Park, IL). The images were collected using the G BOX Chemi systems (Syngene, Frederick, MD).

\section{Cytokine quantitation}

TNF $\alpha$, IL-1 $\beta$, IL-10, and IL-12p70 in the culture supernatants were quantitated by human and mouse Customary Cytokine Arrays following the manufacturer's protocol (MesoScale Diagnostics, Rockville, MD).

\section{LLC mouse model, treatment, and tumor tissue processing}

C57BL/6 mice (female, $8 \sim 10$-week-old, $n=5$ ) were implanted subcutaneously with 0.2 -ml sterile PBS containing $5 \times 10^{6} /$ mouse of LLC into the right flank. The appearance and growth of tumors were monitored twice a week. The greatest longitudinal diameter (length) and the greatest transverse diameter (width) of a palpable tumor were measured to the nearest $0.1 \mathrm{~mm}$ using a caliper. Tumor volume $\left(\mathrm{mm}^{3}\right)$ was calculated by the formula Tumor volume $=$ $\left(\right.$ length $\times$ width $\left.^{2}\right) / 2$. LLC-bearing mice were treated every other day, starting on day 7 , with intratumoral (i.t.) injection of CT alone or in combination with anti-PD-L1 at various doses for 2 weeks. In experiments determining the contribution of lymphocytes to the development of anti-LLC immune defense, LLC-bearing mice were also simultaneously treated intraperitoneal injection of $0.2 \mathrm{ml}$ PBS containing $200 \mu \mathrm{g}$ of either control rat $\operatorname{IgG}$ (clone 2A3, BioXcell, West Lebanon, $\mathrm{NH}$ ), anti-mouse CD4 (clone GK1.5, BioXcell), anti-mouse CD8 $\alpha$ (clone 53-6.72), or anti-mouse NK1.1 (clone PK136, BioXcell). In accordance with the institutional guideline, mice with big tumors (volume $>2000 \mathrm{~mm}^{3}$ ) undergoing necrosis were considered morbid and euthanized.

Tumors resected from LLC-bearing mice treated with $\mathrm{CT}$ alone or in combination with anti-PD-L1 were used for RNA extraction using TRIZol solution (Invitrogen). Alternatively, the tumors were dissociated into single-cell suspensions using an enzymatic cocktail consisting of collagenase I, II, and VI, deoxyribonuclease I, and elastase as previously reported [20]. 


\section{Immunostaining and flow cytometry}

DCs suspended in FACS buffer (PBS containing 0.5\% BSA and $0.05 \% \mathrm{NaN}_{3}$ ) were blocked with $2 \%$ mouse serum on ice for $20 \mathrm{~min}$ and stained with various combinations of fluorophore-conjugated antibodies against human or mouse DC surface markers on ice for $30 \mathrm{~min}$ in the dark. Mouse DCs were stained with FITC-anti-mouse CD86 (clone GL1, TONBO Biosciences, San Diego, CA), PE-anti-mouse CD80 (clone 16-10A1, TONBO), Pacific Blue-anti-mouse CD83 (clone Michel-19, BD), and APCanti-mouse I-A/E (clone M5/114.15.2, eBioscience). Single LLC tumor cell suspensions were stained with FITC-anti-mouse CD4 (clone GK1.5, Tonbo), PerCP-Cy5anti-mouse-B220 (clone RA3-6B2, Tonbo), APC-antimouse-CD11c (clone HL3, BD), eFluor450-anti-mouse CD45 (clone 30-F11, eBioscience), and APC-Cy7-antimouse-CD8 (clone 53-6.7, Tonbo). Data of the stained samples were acquired using an LSR II flow cytometer (BD) and analyzed using the software FlowJo.

\section{Total RNA isolation and CDNA synthesis}

RNA samples from LLC tumors were isolated by a combination use of TRIzol (Invitrogen, Cat: 1,559,026) and an RNeasy Micro Kit RNA (Qiagen, Hilden, Germany, Cat: 74,004). The purity and concentration of the extracted RNA was assessed and measured using absorption at the $260 \mathrm{~nm}$ wavelength with a Nanodrop ND-1000 spectrometer (Nanodrop Technologies, Wilmington, DE). Next, the cDNA was made from the isolated RNA using the $\mathrm{RT}^{2}$ First-Strand Kit (Qiagen, Cat: 330,401).

\section{Quantitative real-time polymerase chain reaction (qPCR)}

The expression of target mouse genes was determined by qPCR using a LightCycler 480 II (Roche Life Sciences, Branford, CT, USA), RT ${ }^{2}$ SYBR Green/ROX qPCR Master Mix (Qiagen, Cat: 330,523), and the specific primer pairs for CXCL9 [Qiagen, Cat: PPM029723-200], CXCL11 [Qiagen, Cat: PPM03192C-200], Granzyme B [Qiagen, Cat: PPM05303F-200], Perforin [Qiagen, Cat: PPM34456B-200], IFN $\gamma$ [Qiagen. Cat: PPM03121A-200], IL-10 [Qiagen, PPM03017C-200], and GAPDH [IDT, Cat:135,048,676]. The cycling conditions for the qPCR were: hot start for $10 \mathrm{~min}$ at $95^{\circ} \mathrm{C}$; amplification for 40 cycles at $95^{\circ} \mathrm{C}$ for $15 \mathrm{~s}, 55^{\circ} \mathrm{C}$ for $35 \mathrm{~s}$, and $72{ }^{\circ} \mathrm{C}$ for $30 \mathrm{~s}$; and cool down for $2 \mathrm{~min}$ at $37^{\circ} \mathrm{C}$. Finally, the expression levels were normalized to those of GAPDH and the data were analyzed using the ${ }^{\Delta \Delta} \mathrm{Ct}$ method through Qiagen's GeneGlobe Data Analysis Center.

\section{Statistical analysis}

All experiments were performed at least three times and the results of one representative experiment or the mean of multiple experiments are shown. The difference between groups in terms of cytokine production was determined by Student's $t$ test. Differences in the in vivo tumor growth were determined by Repeated Measures of ANOVA.

\section{Results}

\section{CT inhibited the proliferation of Lewis lung carcinoma (LLC) cells based on G2/M cell-cycle arrest}

Screening of a dozen of TCM compounds for their capacity to both inhibit tumor cell proliferation and promote human DC maturation identified CT. CT dose-dependently inhibited the proliferation of A549 cells, with a 50\% inhibitory concentration of $0.228 \mu \mathrm{g} / \mathrm{ml}$ (sFig. 1a), and at $10 \mu \mathrm{g} / \mathrm{ml}$, upregulated the expression of surface CD80, CD86, HLA-ABC, and HLA-DR on human monocyte-derived DCs (sFig. 1b). When LLC was tested, CT dose-dependently inhibited its proliferation, with an $\mathrm{IC}_{50}$ at $2.8 \mu \mathrm{g} / \mathrm{ml}$ (Fig. 1a). However, $\mathrm{CT}$ at a wide concentration range did not cause hemolysis of erythrocytes (sFig. 2) or lysis of monocyte-derived macrophages $(\mathrm{M} \varphi)$ (sFig. 3), suggesting that $\mathrm{CT}$ was not cytotoxic for normal cells.

To investigate how CT inhibited LLC proliferation, LLC cells were cultured with various concentrations of CT or $1 \% \mathrm{NaN} 3$ for $24 \mathrm{~h}$ and subsequently stained with FITCconjugated annexin $\mathrm{V}$ and propidium iodide (PI) to detect apoptosis. $\mathrm{NaN}_{3}$ caused apoptotic death of LLC with a dramatic increase in the percentage of annexin V-positive cells (Fig. 1b, right plot). In contrast, even at the concentration $(10 \mu \mathrm{g} / \mathrm{ml})$ that completely inhibited the proliferation of LLC (Fig. 1a), CT did not induce apoptosis of LLC cells (Fig. 1b, left plot).

To determine the effect of $\mathrm{CT}$ on cell-cycle progression, synchronized LLC cells were treated with CT at $0 \sim 2 \mu \mathrm{g} / \mathrm{ml}$ for $24 \mathrm{~h}$ to quantitate the relative fractions of cells in every phase of the cell cycle. CT dose-dependently increased the percentage of cells in G2/M phase with concomitant reduction in the percentage of cells in G0/G1 phase, thus, demonstrating that CT treatment resulted in G2/M arrest of LLC (Fig. 1c).

LLC cells were then treated with various concentrations of CT for $24 \mathrm{~h}$ to identify signaling molecules that regulate cell-cycle progression. CT in a dose-dependent manner elevated the levels of phosphorylated p53, which was 
a

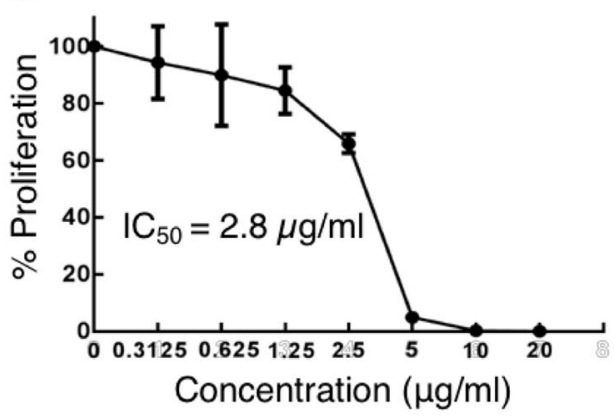

b

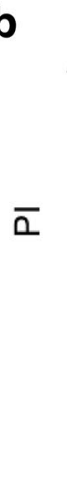

CT $(10 \mu \mathrm{g} / \mathrm{ml})$

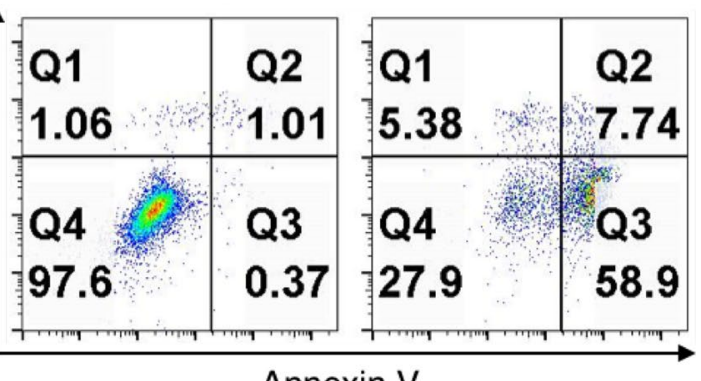

CT $(\mu \mathrm{g} / \mathrm{ml})$

C
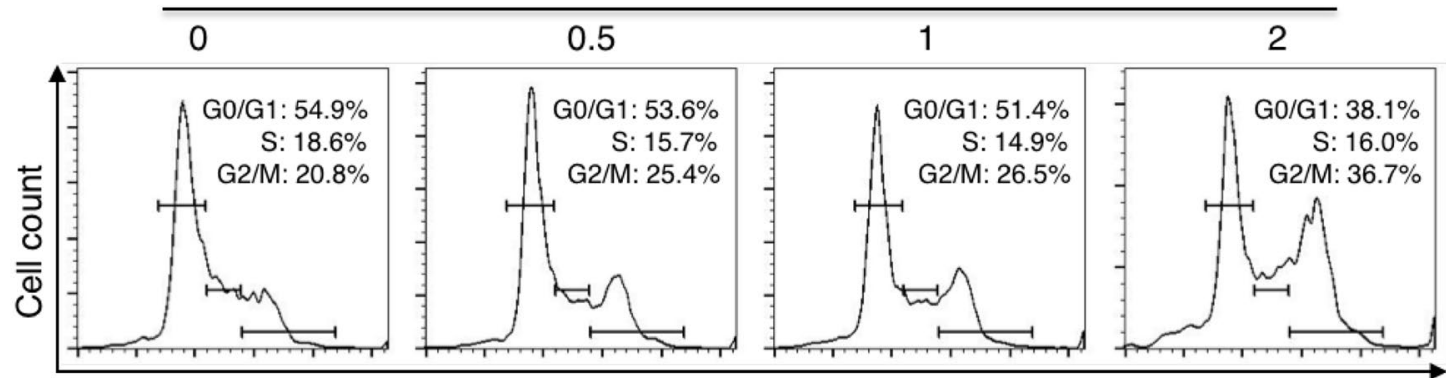

$\mathrm{PI}$

d

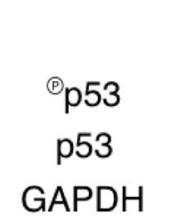

\section{Cyclin B1}

GAPDH

Cdc2 GAPDH
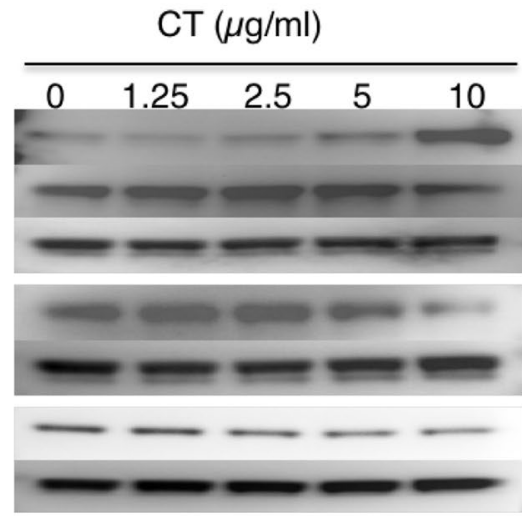

Fig. 1 CT inhibited the proliferation of LLC through G2/M arrest with compatible intracellular signaling events. a LLC cancer cells were treated in triplicate in a 96-well plate for $48 \mathrm{~h}$ in a $\mathrm{CO}_{2}$ incubator with $\mathrm{CT}$ at indicated concentrations and their proliferation assessed by ${ }^{3} \mathrm{H}-\mathrm{TdR}$ incorporation. The $\%$ proliferation was calculated as (CPM with compound - CPM blank)/(CPM without compound - CPM blank) $\times 100$. b LLC cells seeded in a 12-well plate at $3 \times 10^{5} / \mathrm{ml} /$ well were treated with various concentrations of CT or $1 \% \mathrm{NaN}_{3}$ (as a positive control) for $24 \mathrm{~h}$ in a $\mathrm{CO}_{2}$ incubator. Subsequently, the cells were harvested and stained with an apoptosis detection kit. Only the dot plot (PI vs annexin V) of cells treated with $10 \mu \mathrm{g} / \mathrm{ml}$ of CT and $1 \% \mathrm{NaN}_{3}$ is shown. c Synchronized LLC treated

mirrored by a reduction of unphosphorylated $\mathrm{p} 53$, indicating CT activated p53 (Fig. 1d). CT also dose-dependently decreased the levels of cyclin B1 and Cdc2 (Fig. 1e). Therefore, $\mathrm{CT}$ induced the activation of p53 and the consequent

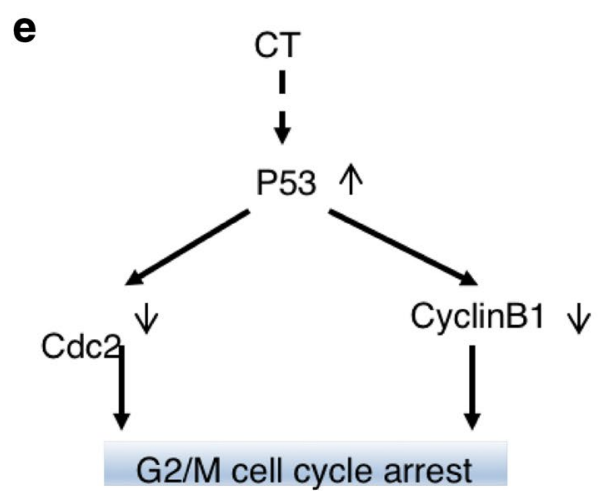

with various concentrations of $\mathrm{CT}$ for $48 \mathrm{~h}$ in a $\mathrm{CO}_{2}$ incubator was stained with PI and subsequently analyzed for cell cycle. The data were graphed using FlowJo. d LLC cells serum-starved for $24 \mathrm{~h}$ were treated with indicated concentrations of CT before lysis in $1 \times$ SDS sample buffer at $10^{7} / \mathrm{ml}$. The samples were separated on a $4-12 \%$ gradient NuPAGETM gel, transferred on a piece of Immobilon ${ }^{\mathrm{TM}}$ membrane, blocked, and reacted with anti-phospho-p53, anti-cyclin B1, or anti-Cdc2. The membrane used for probing phosphor-p53 was stripped and re-probed with anti-p53. After the images were taken, the membranes were stripped and re-probed with anti-GAPDH. e A chart illustrating CT-induced signaling pathways responsible for CTinduced G2/M arrest in LLC cells

downregulation of both $\mathrm{Cdc} 2$ and cyclin B1, which, in turn, prevents cell-cycle progression through the mitotic phase in LLC, resulting in G2/M arrest. CT did not alter p21 level (data not shown). 


\section{CT-induced maturation of mouse DCs in a MyD88-dependent manner}

The effects of CT or LPS on mouse bone marrow-derived DCs were determined. Overlay histograms showed that CT at $5 \mu \mathrm{g} / \mathrm{ml}$ upregulated CD80, CD83, CD86, and I-A/E, indicating that CT induced phenotypic DC maturation (Fig. 2a). Noticeably, CT at $5 \mu \mathrm{g} / \mathrm{ml}$ was even more effective than LPS at $100 \mathrm{ng} / \mathrm{ml}$ (Fig. 2a). In addition, CT stimulated DCs to produce TNF $\alpha$, IL-1 $\beta$, and IL-12p70 in a dose-dependent manner after $24 \mathrm{~h}$ and $48 \mathrm{~h}$ of treatment (Fig. $2 \mathrm{~b}$ ). Since CT did not induce IL-10 production by mouse DCs (Fig. 2b), CT-matured DCs are likely to preferentially induce Th1polarized immune responses, which would favor the induction of antitumor immune responses.

To identify the CT-triggered signaling events, mouse bone marrow-derived DCs treated with CT at $10 \mu \mathrm{g} / \mathrm{ml}$ were analyzed for the activation of NF-kB and MAPKs. CT decreased I- $\kappa \mathrm{B} \alpha$ level, which became obvious within $10 \mathrm{~min}$ (Fig. 3a, upper panel). Re-probing the same membrane with anti-GAPDH revealed that the reduction of I- $\kappa \mathrm{B} \alpha$ was not due to uneven loading (Fig. 3a, lower panel). In addition, CT treatment also increased phosphorylation of p65 in DCs (Fig. 3b). Determination of the effect of CT on the three major MAPKs revealed that $\mathrm{CT}$ in a time-dependent manner lowered phosphorylated Erks (Fig. 3c). In contrast, CT induced phosphorylation of p38 and JNK with different kinetics which peaked at 90 and $10 \mathrm{~min}$, respectively (Fig. 3d, e). Therefore, CT activated NF-kB, p38, and JNK, but not Erks, in mouse DCs.

To gain further insight into the mechanistic basis of CTinduced DC maturation, WT, TLR $4^{-/}$, and $\mathrm{MyD} 88^{-/-}$DCs were treated in parallel with CT at $5 \mu \mathrm{g} / \mathrm{ml}$ or LPS (100 ng/ $\mathrm{ml}$ ) for $48 \mathrm{~h}$ and the expression of surface markers was determined. As shown in Fig. 4a, CT induced similar upregulation of CD80, CD83, CD86, and I-A/E in WT and a

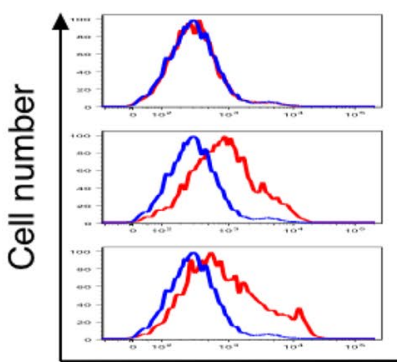

CD83

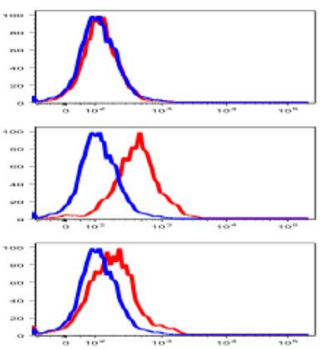

CD86

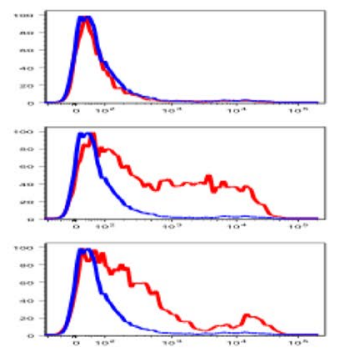

I-A/E

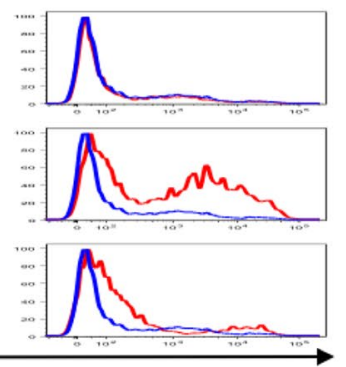

CT $(0.5 \mu \mathrm{g} / \mathrm{ml})$

CT $(5 \mu \mathrm{g} / \mathrm{ml})$

LPS $(100 \mathrm{ng} / \mathrm{ml})$

Fluorescence intensity
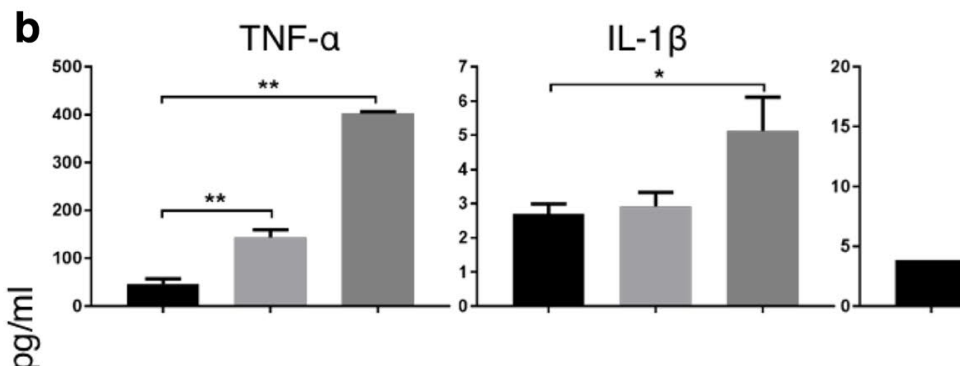

IL-10

IL-12

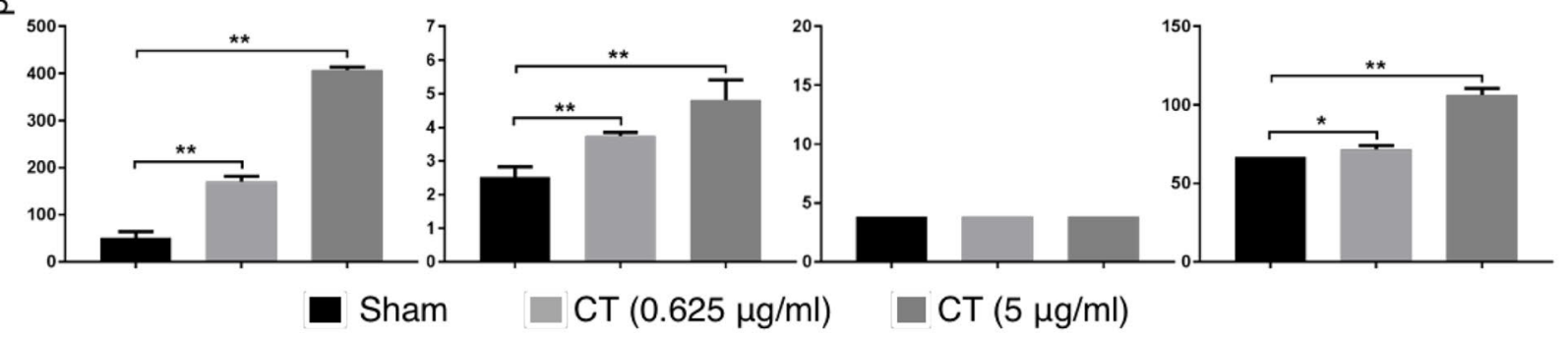

$48 \mathrm{~h}$

Fig. 2 CT induced maturation of mouse DCs. a Mouse bone marrow-derived DCs were incubated in a $\mathrm{CO}_{2}$ incubator for $48 \mathrm{~h}$ with or without CT or LPS at the concentrations specified before they were immunostained for detection of surface marker (CD80, CD83, CD86, and I-A/E) expression by flow cytometry. Shown are the overlay histograms of sham (blue line) and treated (red line) DCs. b Mouse bone marrow-derived DCs were cultured in the absence (sham) or presence of various concentrations of CT for 24 or $48 \mathrm{~h}$ before the supernatants were harvested for the measurement of indicated cytokines. Shown is the average (mean $\pm \mathrm{SD}$ ) of three independent experiments. ${ }^{*} p<0.05$ and $* * p<0.001$ 


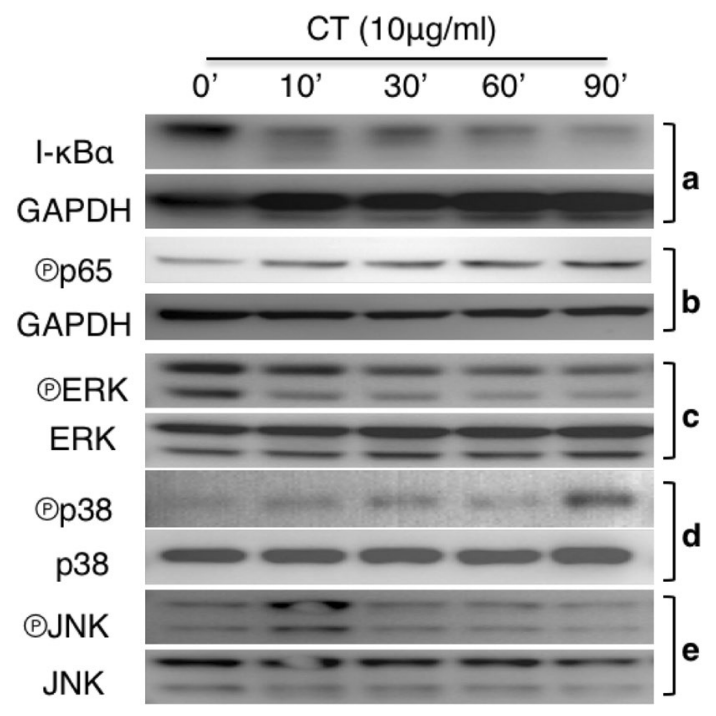

Fig. $3 \mathrm{CT}$ regulation of NF- $\mathrm{BB}$ and MAPK activation. a Mouse bone marrow-derived DCs treated with $10 \mu \mathrm{g} / \mathrm{ml}$ of CT for the indicated time periods were solubilized in $1 \times$ SDS sample buffer at $10^{7} /$ $\mathrm{ml}$. The samples were separated on a $4-12 \%$ gradient NuPAGETM gel, transferred on a piece of Immobilon ${ }^{\mathrm{TM}}$ membrane, blocked, and treated with anti-IкB $\alpha(\mathbf{a})$, anti-phospho-p65 (b), anti-phospho-Erks (c), anti-phospho-p38 (d), or anti-phospho-JNK (e). After the images were taken, the membranes were stripped and re-probed with antiGAPDH, anti-Erks, anti-p38, and anti-JNK, respectively

$\mathrm{TLR}^{-/-}$DCs, indicating that the DC-maturing effect of CT was not dependent on TLR4. These data also ruled out potential endotoxin contamination of CT used in the present study. In contrast, CT-induced upregulation of CD86 and I-A/E was markedly reduced in $M y D 88^{-/-}$DCs (Fig. 4a). As anticipated, LPS-induced upregulation of CD80, CD83, CD86, and I-A/E occurred in WT DCs, but was completely deficient in $\mathrm{TLR}^{-/-}$DCs and markedly reduced in $M y D 88^{-/-}$DCs (Fig. 4a). The production of proinflammatory cytokines (TNF- $\alpha$, IL-1 $\beta$, or IL-12p70) was absent in LPS-stimulated $T L R 4^{-I-}$ DCs, but there was no reduction in CT-treated TLR $4^{-1-}$ DCs (Fig. 4b, upper panel). In contrast, $M y D 88^{-/-}$DCs showed inhibition of both CT- and LPSinduced TNF- $\alpha$, IL-1 $\beta$, and IL-12p70 production (Fig. 4b, lower panel). These results demonstrate that CT induces DC maturation in an MyD88-dependent manner.

\section{Therapeutic antitumor effect of CT on LLC tumors}

C57BL/6 mice bearing established subcutaneous LLC tumors on the flank were treated with intratumoral (i.t.) injection of CT at different doses every other day for 2 weeks and the growth of tumors was monitored. CT significantly inhibited the growth of LLC tumors at $100 \mu \mathrm{g}$ /mouse (Fig. 5a). Lung tumor cells and tumor-infiltrating antigenpresenting cells express PD-L1, which, by interacting with PD-1 on T cells, can inactivate the effector functions of both
$\mathrm{CD} 4^{+}$Th1 $\mathrm{T}$ cells and $\mathrm{CD} 8{ }^{+} \mathrm{CTLs}$, leading to the evasion of antitumor immune responses [21, 22]. To block this potential inhibitory pathway, we investigated whether a combination of CT and anti-PD-L1 antibody would exert a more robust therapeutic effect on LLC tumors. The combination of i.t. injection of CT and anti-PD-L1 at $10 \mu \mathrm{g} /$ mouse twice weekly for 2 weeks initially arrested LLC growth, and subsequently caused LLC tumors to shrink and to be eliminated (Fig. 5b). Anti-PD-L1 at $10 \mu \mathrm{g} /$ mouse twice weekly alone did not eliminate LLC tumors (data not shown). All LLCbearing mice treated with i.t. PBS died by day 40 , while those treated with CT survived until day 60 , a significant improvement over PBS-treated group (Fig. 5c). Strikingly, all LLC-bearing mice treated with the combination of CT and anti-PD-L1 became tumor-free (Fig. 5c).

The cured tumor-free mice were subcutaneously inoculated with LLC and EG7 mouse thymoma cells on the contralateral flanks, and the formation of solid tumors on both flanks was monitored. All the mice formed solid EG7 tumors, whereas none of the mice formed LLC tumors, as illustrated by one of the mice photographed after euthanasia on day 20 (Fig. 5d). Thus, the mice cured from LLC in response to treatment with CT and anti-PD-L1 acquired long-term LLC-specific immunity.

LLC-bearing mice treated with CT and/or anti-PD-L1 showed a significant increase in the infiltration of $\mathrm{CD} 45^{+}$ leukocytes, particularly $\mathrm{CD} 4^{+}$and $\mathrm{CD} 8^{+} \mathrm{T}$ cells, in their tumors (Fig. 6a). In contrast, the percentage of DCs $\left(\mathrm{CD} 11 \mathrm{c}^{+} / \mathrm{CD} 45^{+}\right)$in the tumor tissue significantly decreased in response to treatment with $\mathrm{CT}$ or CT plus anti-PD-L1 (Fig. 6a), suggesting that $\mathrm{CT}$ treatment caused in vivo DC maturation, since mature DCs migrate from tumors to draining lymph nodes [20]. qPCR analysis of LLC tumors revealed that treatment with $\mathrm{CT}$ significantly elevated the expression of CXCL9 and CXCL11 in LLC tumors, two chemokines responsible for the recruitment of Th1 T cells (Fig. 6b). In addition, $\mathrm{CT}$ treatment also elevated the expression of granzyme B, perforin, and IFN $\gamma$ in the tumors (Fig. 6b), thus, demonstrating CT promotion of a Th1-polarized tumor microenvironment critical for combatting tumors. Treatment with CT in combination with anti-PD-L1 further enhanced the expression of CXCL9, CXCL11, granzyme B, perforin, and IFN $\gamma$ (Fig. 6b). No significant change was detected for IL-10 expression in LLC tumors in response to treatment with CT or CT plus anti-PD-L1 (Fig. 6b).

To determine whether the therapeutic antitumor effect of CT was due to the generation of antitumor immunity, depleting antibody against mouse $\mathrm{CD} 4, \mathrm{CD} 8$, or NK cells was used together with treatment with CT plus anti-PDL1. LLC tumor growth was halted by treatment with CT plus anti-PD-L1; however, simultaneous administration of anti-CD8 antibody completely abolished the therapeutic effect of CT plus anti-PD-L1 (Fig. 6c), demonstrating the 
a

CD80

CD83

CD86
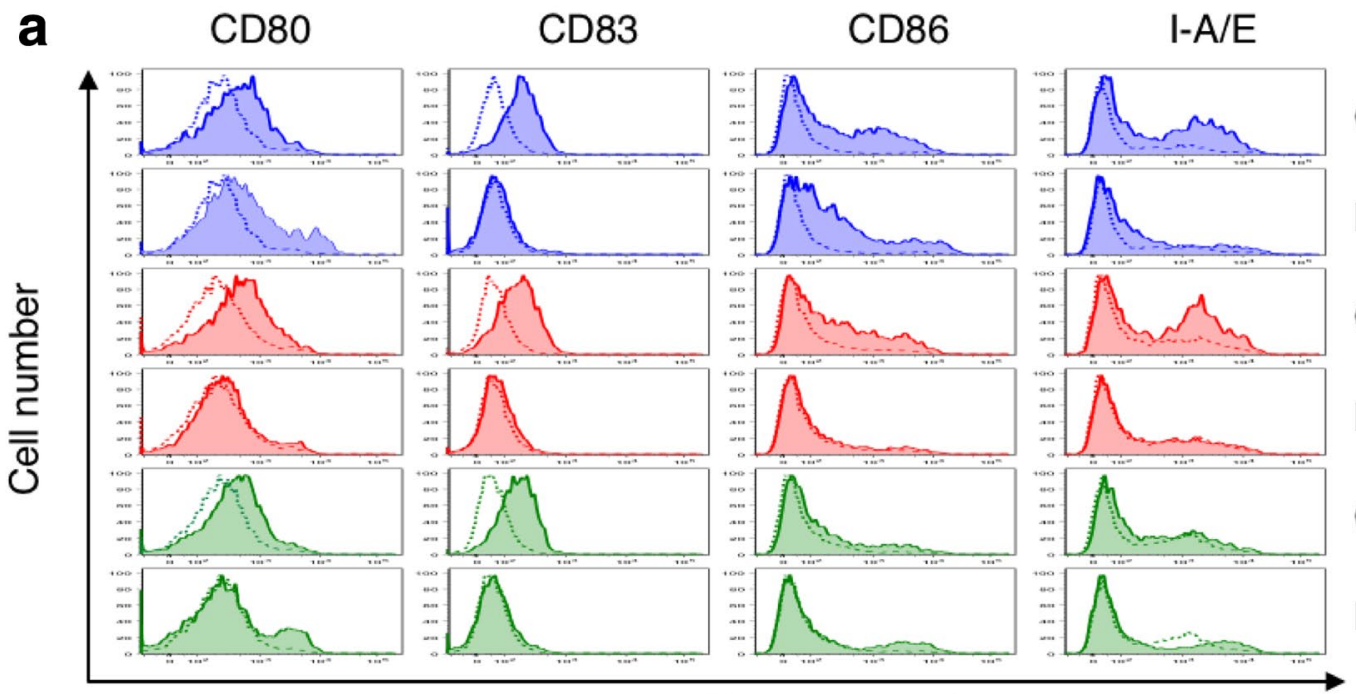

$\left.\begin{array}{l}\text { CT } \\ \text { LPS }\end{array}\right]$

WT

Fluorescence intensity

b

TNF-a

IL-1 $\beta$

IL-12
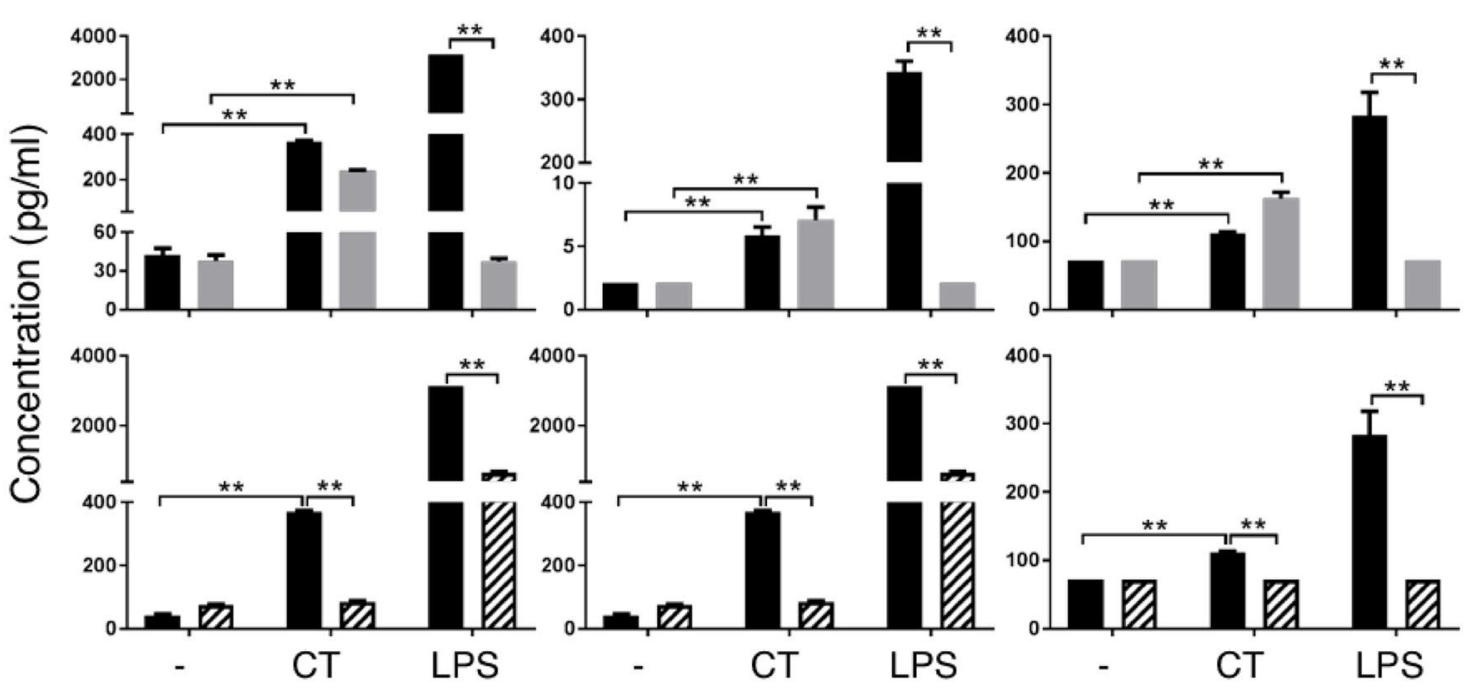

WT

$\mathrm{TLR}^{-1-}$

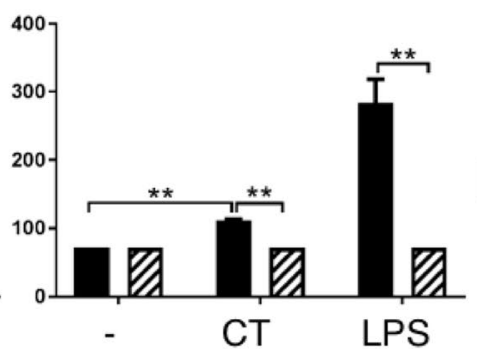

WT

DyD88 ${ }^{-1-}$

Fig. 4 Comparison of CT-induced maturation of wild-type (WT), $\mathrm{TLR}^{-/-}$, and $\mathrm{MyD}^{-1-}$ mouse DCs. a, WT (C57BL/6), $\mathrm{TLR}^{-1-}{ }^{-1}$, and $\mathrm{MyD} 88^{-1-}$ mouse DCs were incubated in a $\mathrm{CO}_{2}$ incubator for $48 \mathrm{~h}$ with CT $(5 \mu \mathrm{g} / \mathrm{ml})$ or LPS $(100 \mathrm{ng} / \mathrm{ml})$ before they were immunostained for the detection of surface marker (CD80, CD83, CD86, and I-A/E) expression by flow cytometry. Shown are the overlay histograms of sham (blue line) and treated (red line) DCs. b, Mouse bone marrow-derived DCs were cultured in the absence (sham) or presence of CT $(5 \mu \mathrm{g} / \mathrm{ml})$ or LPS $(100 \mathrm{ng} / \mathrm{ml})$ for $48 \mathrm{~h}$ and the supernatants were harvested to assay the indicated cytokines. Shown is the average (mean $\pm \mathrm{SD}$ ) of three independent experiments. $* p<0.05$ and $* * p<0.001$ critical contribution of CD8 T cells to the antitumor effect of CT. Simultaneous administration of anti-CD4 antibody also partially negated the therapeutic effect of CT plus anti-PD-L1 (Fig. 6c), suggesting that CD4 T cells also contributed. In contrast, NK cells did not seem to significantly contribute, since simultaneous administration of anti-NK1.1 antibody did not affect the therapeutic antitumor effect of CT plus anti-PD-L1 (Fig. 6c).

\section{Discussion}

In this study, we discovered the unique capacity of CT to induce the maturation of both human and mouse DCs (sFig. 1 and Figs. 2, 4). The CT preparation used in this study contained no contaminating endotoxin, since it stimulated the maturation of both WT and TLR4 knockout 


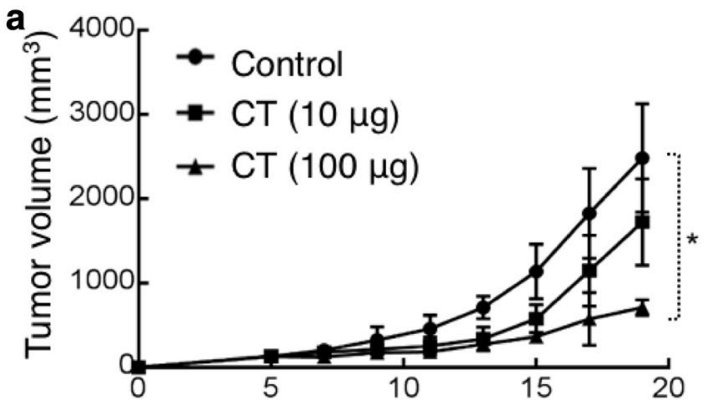

Days after LLC tumor inoculation

\section{b}

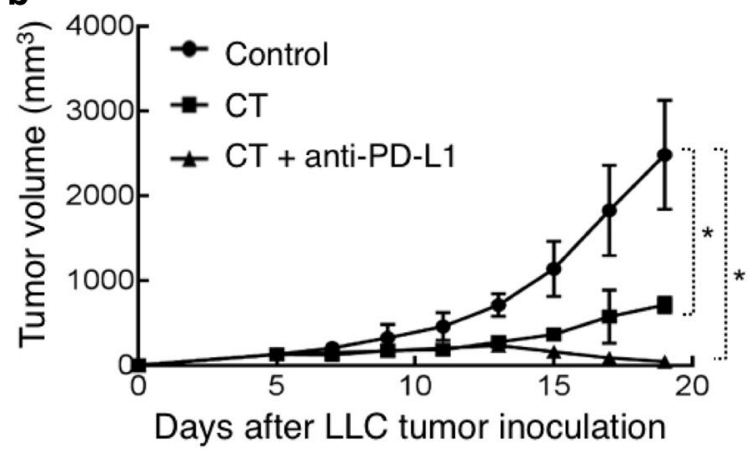

C

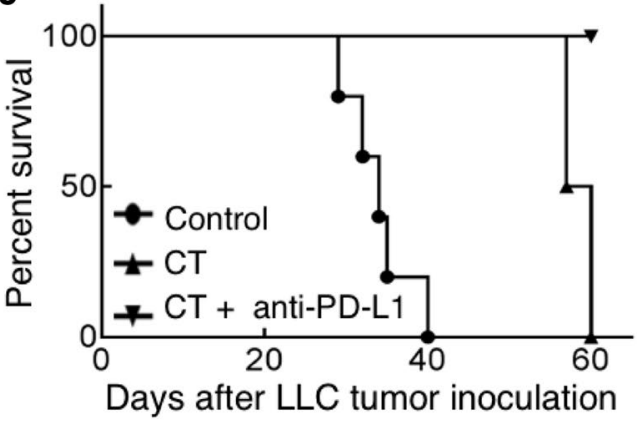

d

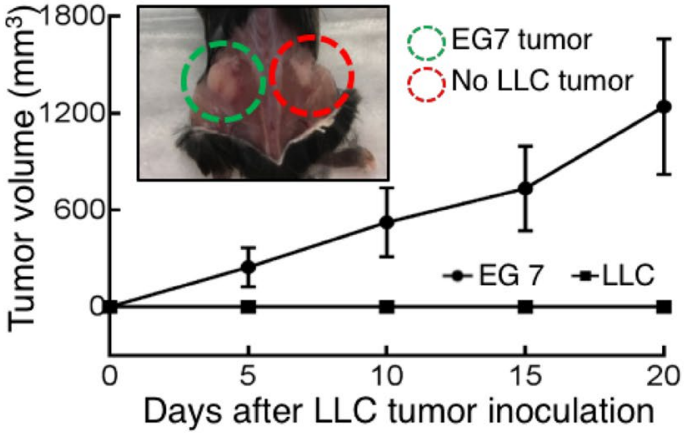

Fig. 5 Therapeutic effect of CT on mouse LLC. a C57BL/6 (female, 8 -week-old, $n=5$ ) were subcutaneously inoculated with $5 \times 10^{6} \%$ mouse of LLC into the right flank on day 1. From day 7, LLC-bearing mice were treated every other day with i.t. injection of PBS (control) or CT at the doses as indicated for 2 weeks. Tumor growth (mean $\pm \mathrm{SD}$ ) was recorded $\left({ }^{*} p<0.05\right)$. b, c, LLC-bearing mice were prepared as in A and treated, starting on day 7, with i.t. injection of CT (100 $\mu \mathrm{g} /$ mouse) every other day or CT combined with i.t. injection of

DCs. Importantly, CT at concentrations capable of promoting DC production of TNF $\alpha$, IL- $1 \beta$, and IL-12 did not induce IL-10 production (Fig. 2). This is a remarkable feature for $\mathrm{CT}$ in the context of cancer treatment for two reasons. First, this suggests that DCs matured by CT preferentially promote Th1-type immune responses that are important for antitumor immune defenses. Although the induction of Th1-type immune responses is favored by DC-derived IL-12, it is inhibited by DC-derived IL-10 through the induction of Tregs [23, 24]. Second, the failure of IL-10 production by mouse DCs in tumor tissues in response to $\mathrm{CT}$ would also reduce the level of immunosuppression in the tumor microenvironment, since IL-10 is a potent immunosuppressive cytokine $[6,7]$.

The mechanism of CT-induced DC maturation involves downregulation of I- $\kappa \mathrm{B} \alpha$ and upregulation of phosphorylated p65, p38, and JNK in DCs (Fig. 3). Reduction of I- $\kappa \mathrm{B} \alpha$ level and phosphorylation of p65 allow p50/p65 complex to translocate from the cytosol to the nucleus to interact with promoters with NF-kB-binding sites, which, in turn, promotes the transcription of many cytokine genes such as
anti-PD-L1 antibody (10 $\mu \mathrm{g} /$ mouse) twice weekly for 2 weeks. Tumor growth (b) and mouse survival (c) were recorded. $\mathbf{d}$ The mice cured of LLC by treatment with CT + anti-PD-L1 in c were s.c. inoculated with $5 \times 10^{6}$ mouse of LLC in the right flank and EG7 thymoma in the contralateral flank. The growth of tumors on both flanks was recorded. All the mice grew EG7 tumors without LLC tumors, with the photo image confirmation of one euthanized mouse at the end of the experiment (insert)

TNF $\alpha$, IL-1 $\beta$, and IL-12 $[25,26]$. Activation of p38 and JNK in DCs is critical for the upregulation of the expression of surface costimulatory and MHC molecules as well as production of IL-12 [23, 25]. Therefore, both NF- $\kappa B$ and MAPK signaling pathways are involved in CT-induced DC maturation. The signaling pathway upstream of NF-кB and MAPK requires MyD88, because CT-induced DC upregulation of CD86 and I-A/E as well as induction of TNF $\alpha$, IL-1 $\beta$, and IL-12 were greatly compromised in $\mathrm{MyD} 88^{-1-} \mathrm{DCs}$ (Fig. 4). How CT stimulates a MyD88-dependent signaling pathway that results in DC maturation is under current investigation. Since MyD88 is the adaptor protein that acts downstream of many Toll-like receptors and the IL-1 receptor superfamily, it is speculated that CT may use one of the receptors.

The anti-proliferative effect on both human (sFig. 1) and mouse (Fig. 1) lung cancer cells was not based on an overall cytotoxic effect, because CT at concentrations as high as $20 \mu \mathrm{g} / \mathrm{ml}$ did not lyse human erythrocytes and was not cytotoxic for human macrophages (sFigs. $2 \& 3$ ). Inhibition of LLC proliferation was based on induction of cell-cycle 


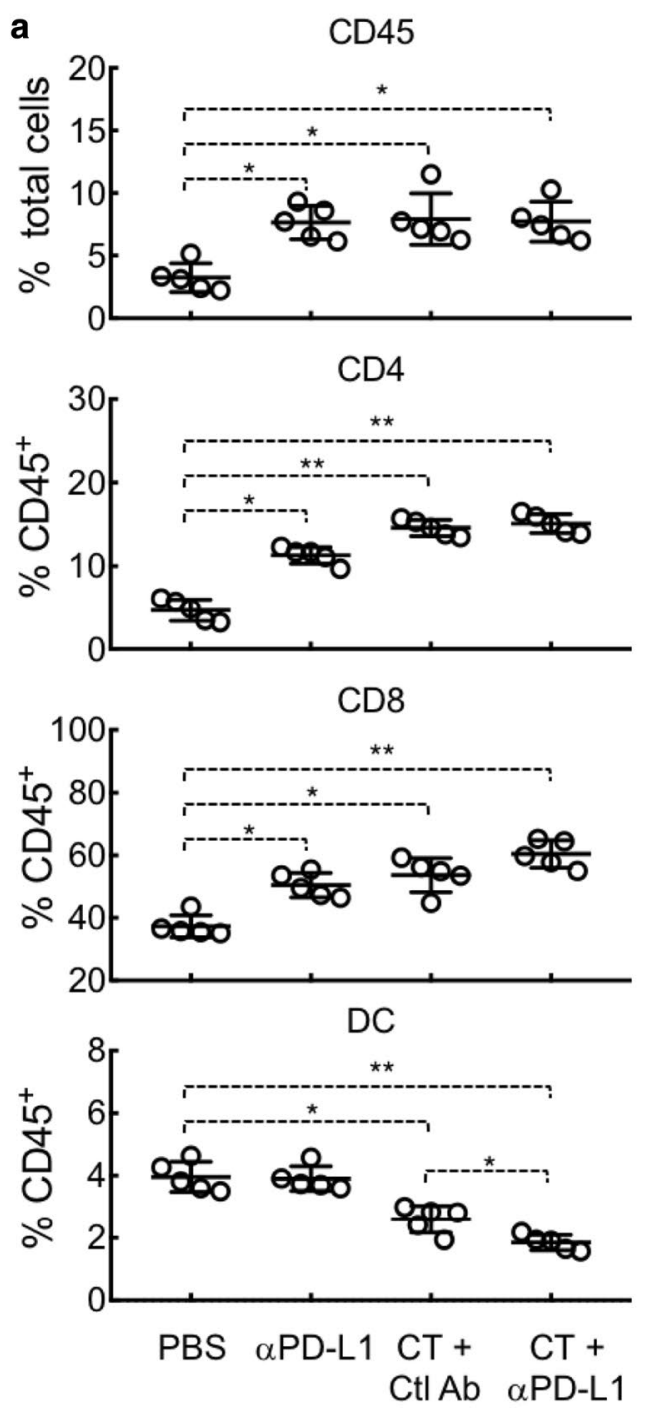

b
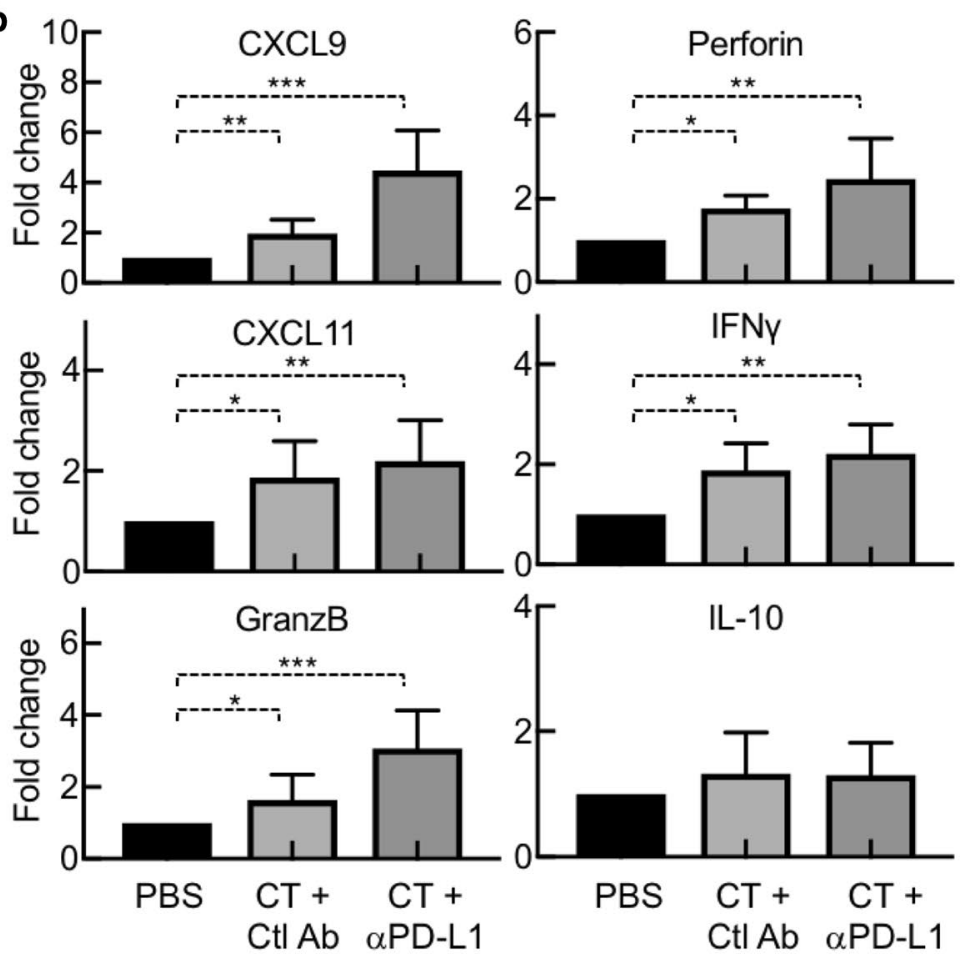

c

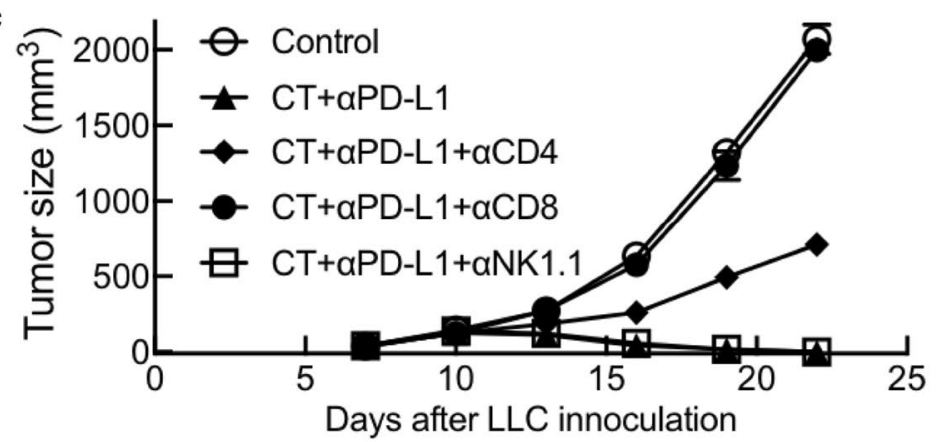

Fig. 6 Dependence of CT's therapeutic antitumor effect on T-cellmediated immune defense. LLC-bearing C57BL/6 (8 weeks old, $n=5)$ mice were treated every other day with i.t. injection of CT (100 $\mu \mathrm{g} /$ mouse) and anti-PD-L1 ( $\alpha$ PD-L1, $10 \mu \mathrm{g} / \mathrm{mouse})$ alone or in combination starting on day 7. Rat $\operatorname{IgG} 2 \mathrm{~b}$ was used as the control antibody ( $\mathrm{Ctl} \mathrm{Ab})$. a LLC tumors removed $24 \mathrm{~h}$ after the third treatment were dissociated into single-cell suspension, which were immunostained and analyzed for the abundance of various subsets of leuko- cytes. b RNA samples isolated from LLC tumors removed $24 \mathrm{~h}$ after the third treatment were quantitated for expression of indicated genes at the mRNA level by qPCR. Data in $\mathbf{a}, \mathbf{b}$ are shown as the average (mean $\pm \mathrm{SD}$ ) of each group, with $* p<0.001$ and $* * p<0.0001$ by $t$ test. c LLC-bearing mice were additionally treated with i.p. injection of indicated $200 \mu \mathrm{g}$ of leukocyte-depleting antibody once every 3 days, starting on day 5 . Tumor size was monitored twice per week and tumor growth curve was plotted arrest at the G2/M phase (Fig. 1). Measurement of cell-cycle regulators revealed that CT dramatically activated p53 in LLC cells (Fig. 1d). p53 is an important tumor suppressor that regulates both $\mathrm{G} 1$ and G2/M cell-cycle checkpoints of mammalian cells $[27,28]$. p53 induces $\mathrm{G} 1$ arrest by promoting the transcription and expression of $\mathrm{p} 21^{\mathrm{WAF} 1 / \mathrm{CIP} 1}$, a cyclin-dependent kinase (Cdk) inhibitor [27, 29]. Binding of $\mathrm{p} 21^{\mathrm{WAF} 1 / \mathrm{CIP} 1}$ to a number of cyclin/Cdk complexes inhibits their kinase activities, resulting in hypophosphorylation of $\mathrm{Rb}$, sequestration of $\mathrm{E} 2 \mathrm{~F}$, and failure to activate
E2F-responsive genes leading to $\mathrm{G} 1$ arrest $[28,30]$. Consistent with the fact that CT did not induce G1 arrest in LLC cells (Fig. 1d), CT treatment of LLC cells did not alter the cellular levels of $\mathrm{p} 21^{\mathrm{WAF} 1 / \mathrm{CIP} 1}$ or the phosphorylation of $\mathrm{Rb}$ (data not shown). p53 transcriptionally represses cyclin B1 and inhibits $\mathrm{Cdc} 2$, and because the cyclin B1/Cdc2 complex is required for cell-cycle entry into mitosis, this results in G2/M arrest [27, 28, 31]. In full agreement with CT-induced G2/M arrest, CT-induced activation of p53 was also accompanied by reduction of cyclin B1 and Cdc2 (Fig. 1d). Thus, 
the signaling pathway responsible for CT-induced G2/M arrest in LLC cells involves activation of p53 that downregulates cyclin $\mathrm{B} 1$ and $\mathrm{Cdc} 2$, leading to $\mathrm{G} 2 / \mathrm{M}$ cell-cycle arrest (Fig. 1e). It was previously reported that treatment of human lung cancer cell line A549 with CT also resulted in downregulation of cyclin B1 and G2/M cell-cycle arrest [32]. Therefore, it is likely that induction of G2/M cell-cycle arrest is a common pathway for CT-induced inhibition of proliferation of both human and mouse lung cancer cells. It remains to be determined how CT causes phosphorylation and activation of p53 in LLC lung cancer cells.

In addition to inducing G2/M arrest, CT treatment also caused apoptotic cell death of human lung cancer A549 cells (data not shown), confirming a previous report [32]. Very recently, CT has also been reported to inhibit the proliferation of A549 human lung cancer cells through a signaling pathway involving induction of reactive oxygen species, activation of JNK, downregulation of MTOR, and ultimately formation of pro-death autophagy [33]. Irrespective of the underlying mechanistic basis, administration of CT into nude mice harboring human lung cancers inhibited the growth of xenograft tumors [32,33], indicating that CT exhibits direct anti-proliferative effect against lung cancer cells in vivo.

Given the unique dual effects of CT on lung cancer cells and DCs, we hypothesized that CT would exhibit immunotherapeutic anti-lung cancer effect in immunocompetent mice by augmenting the generation of antitumor immunity. Indeed, CT exhibited a remarkable therapeutic effect on established LLC tumors when used alone and more so in combination with anti-PD-L1 antibody in mice (Fig. 5). It is very encouraging that mice bearing established s.c. LLC tumors were cured by a combination of CT and low doses of anti-PD-L1 (Fig. 5). The data showing that the resultant tumor-free mice were resistant to re-challenge with LLC, but not B16 melanoma, demonstrate that treatment with CT plus low doses of anti-PD-L1 promoted the generation of LLC-specific antitumor immune responses and immunological memory.

How does the combination of CT and anti-PD-L1 eradicates LLC tumors? CT administered into LLC tumors would likely promote LLC-specific immune responses by stimulating the maturation of LLC-infiltrating DCs, followed by DC trafficking from tumor tissue to the draining lymph nodes, and the induction of generation of LLC-specific effector T cells. Once generated in the draining lymph nodes, LLC-specific effector CD4 (Th1) and CD8 (CTLs) would migrate into tumor tissue to produce IFN $\gamma$ and kill tumor cells. In agreement with this scenario, CT treatment of LLC tumors resulted in maturation of DC and significantly lowered the abundance of DCs in the tumors (Fig. 6a), presumably due to the migration of mature DCs to draining lymph nodes [20]. In addition, LLC tumors treated with CT showed elevated infiltration of T cells (Fig. 6a) and a profile of gene expression typical of Th1 polarization (Fig. 6b). Furthermore, the therapeutic anti-LLC effect of CT in combination with anti-PD-L1 was remarkably reduced by depleting CD4 or CD8 T cells (Fig. 6c). In addition to promoting tumor killing, IFN $\gamma$ also upregulates PD-L1 expression on tumor cells, which, in turn, inhibits the effector function of CTLs by interacting with PD1 on CTLs [34, 35]. Administration of anti-PD-L1 could blockade PD-L1-PD1 interaction to prevent silencing of CTLs, allowing sustained killing of LLC tumor cells. Thus, combination of CT and anti-PD-L1 promotes more robust Th1 polarized environment in the tumors (Fig. 6b) and manifests more potent antitumor effects than CT alone, resulting in complete elimination of LLC tumors (Figs. 5, 6c). Since CT is also capable of inhibiting the proliferation of human A549 lung cancer cells (sFig. 1, 32, 33 and Refs. [32, 33]) and inducing the maturation of human DCs (sFig. 1), CT may be similarly effective against human lung cancers. Therefore, CT alone or in combination with anti-PDL1 may provide a new treatment for human lung cancers.

CT has previously been reported to inhibit the proliferation of diverse types of tumor cells in vitro, such as prostate cancer [36-38], human rhabdomyosarcoma [39], human leukemia [40], breast cancer [41], pancreatic cancer [42], and colon cancer [43]. A very recent paper even reported that $\mathrm{CT}$ treatment of prostate cancer stem cells could inhibit their proliferation and tumorigenesis by downregulating the expression of stemness genes including Nanog, SOX2, Oct4, and CXCR4 [44]. We have confirmed that CT can inhibit the proliferation of multiple human and mouse cancer cell lines (data not shown). Although it remains to be established, it is likely that CT may promote antitumor immunity to other types of cancers in addition to lung cancer. More recent studies reveal that $\mathrm{CT}$ is also effective against mouse Hepa1-6 hepatoma as described in a parallel paper by Han et al. entitled "Inhibition of murine hepatoma tumor growth by cryptotanshinone involves TLR7-dependent activation of macrophages" (Cancer Immunol Immunother, 2019).

In conclusion, we have identified a TCM-derived compound $\mathrm{CT}$ with unique dual capabilities of inhibiting the proliferation of lung cancer cells and inducing DC maturation. CT is effective for the treatment of established LLC cancers alone or even more effectively in combination with anti-PDL1 in immunocompetent mice. Since the cured mice exhibit specific immunity to the treated tumors, this represents the first report that the enhancement of antitumor immunity by $\mathrm{CT}$ is a crucial contributor to its therapeutic efficacy.

\section{Cell line authentication}

All cell lines used in the present study were obtained from the American Type Culture Collection (Manassas, VA). The cell lines were expanded and cryopreserved according 
to the culture and cryopreserving conditions recommended by American Type Culture Collection. Lewis lung carcinoma (LLC) cell line was passaged and maintained in DMEM medium (Meditech, Manassas, VA) supplemented with 10\% FBS (Hyclone, Logan, UT), 2 mM L-glutamine, $25 \mathrm{mM}$ HEPES, $100 \mathrm{U} / \mathrm{ml}$ penicillin, and $100 \mu \mathrm{g} / \mathrm{ml}$ streptomycin. A549, a human lung carcinoma cell line, and EG7, a cell line derived from EL4 thymoma, were passaged and maintained in RPMI 1640 medium (Meditech) supplemented with $10 \%$ FBS, $2 \mathrm{mM}$ glutamine, $25 \mathrm{mM}$ HEPES, $1.5 \mathrm{~g} / \mathrm{l}$ sodium bicarbonate, $4.5 \mathrm{~g} / \mathrm{l}$ glucose, $1 \mathrm{mM}$ sodium pyruvate, $100 \mathrm{U} / \mathrm{ml}$ penicillin, $100 \mu \mathrm{g} / \mathrm{ml}$ streptomycin, and $50 \mu \mathrm{M} 2-\mathrm{ME}$. For any experiment involving the use of a cell line, one of the cryopreserved vials was freshly thawed and passaged for three times before the cells were used, and, therefore, cell line authentication was not necessary.

Acknowledgements The authors thank Drs. Libin Jia \& Jeffery White at the Office of Cancer Complementary and Alternative Medicine (OCCAM) of the National Cancer Institute (Bethesda, MD, USA) and Drs. Jie Li \& Wei Hou at Guang An Men Hospital of China Academy of Chinese Medical Sciences (Beijing, China) for their invaluable support on this research project.

Author contribution SL, HL, DY, and JJO contributed to the conception and design; SL, ZH, SH, and DY contributed to the development of methodologies and acquisition of data; SL, ZH, ALT, HL, DY, and JJO contributed to Analysis and interpretation of data; SL, DY, and JJO wrote the manuscript; DY and JJO were responsible for study supervision.

Funding This project has been funded in part with Federal funds from the Frederick National Lab, National Institutes of Health, under Contract No. HHSN261200800001E. The content of this publication does not necessarily reflect the views or policies of the Department of Health and Human Services, nor does mention of trade names, commercial products, or organizations imply endorsement by the U.S. Government. This research was supported in part by the Intramural Research Program of NIH, Frederick National Lab, Center for Cancer Research. The publisher or recipient acknowledges right of the U.S. Government to retain a nonexclusive, royalty-free license in and to any copyright covering the article.

\section{Compliance with ethical standards}

Conflict of interest The authors declare that they have no conflict of interest.

Ethical approval All experiments with mice were performed in compliance with the principles and procedures outlined in the National Institutes of Health Guide for the Humane Care and Use of Animals and were approved by the National Cancer Institute at Frederick Animal Care and Use Committee (\#16-294).

Statement of human/animal rights C57BL/6 mice were obtained from Charles River (Frederick, MD). TLR4 ${ }^{-l-}$ and MyD $88^{-/-}$mice were purchased from the Jackson Laboratory (Bar Harbor, ME). Mice were housed under specific pathogen-free conditions with water and food given ad libitum.
Open Access This article is distributed under the terms of the Creative Commons Attribution 4.0 International License (http://creativeco mmons.org/licenses/by/4.0/), which permits unrestricted use, distribution, and reproduction in any medium, provided you give appropriate credit to the original author(s) and the source, provide a link to the Creative Commons license, and indicate if changes were made.

\section{References}

1. Torre LA, Bray F, Siegel RL, Ferlay J, Lortet-Tieulent J, Jemal A (2015) Global cancer statistics, 2012. CA Cancer J Clin 65:87108. https://doi.org/10.3322/caac. 21262

2. Chan BA, Hughes BG (2015) Targeted therapy for non-small cell lung cancer: current standards and the promise of the future. Transl Lung Cancer Res 4:36-54. https://doi.org/10.3978/j. issn.2218-6751.2014.05.01

3. La-Beck NM, Jean GW, Huynh C, Alzghari SK, Lowe DB (2015) Immune checkpoint inhibitors: new insights and current place in cancer therapy. Pharmacotherapy 35:963-976. https://doi. org/10.1002/phar.1643

4. Burnet FM (1959) The Clonal selection theory of acquired immunity. Cambridge University Press, Cambridge

5. Hanahan D, Weinberg RA (2011) Hallmarks of cancer: the next generation. Cell 144:646-674. https://doi.org/10.1016/j. cell.2011.02.013

6. Zou W (2005) Immunosuppressive networks in the tumour environment and their therapeutic relevance. Nat Rev Cancer 5:263-274

7. Kissick HT, Sanda MG (2015) The role of active vaccination in cancer immunotherapy: lessons from clinical trials. Curr Opin Immunol 35:15-22. https://doi.org/10.1016/j.coi.2015.05.004

8. Thomas A, Giaccone G (2015) Why has active immunotherapy not worked in lung cancer? Ann Oncol 26:2213-2220. https://doi. org/10.1093/annonc/mdv323

9. Schvartsman G, Ferrarotto R, Massarelli E (2016) Checkpoint inhibitors in lung cancer: latest developments and clinical potential. Ther Adv Med Oncol 8:460-473. https://doi. org/10.1177/1758834016661164

10. Harimoto H, Shimizu M, Nakagawa Y, Nakatsuka K, Wakabayashi A, Sakamoto C, Takahashi H (2013) Inactivation of tumor-specific CD8(+) CTLs by tumor-infiltrating tolerogenic dendritic cells. Immunol Cell Biol 91:545-555. https://doi.org/10.1038/ icb. 2013.38

11. Krempski J, Karyampudi L, Behrens MD, Erskine CL, Hartmann L, Dong H, Goode EL, Kalli KR, Knutson KL (2011) Tumorinfiltrating programmed death receptor- $1+$ dendritic cells mediate immune suppression in ovarian cancer. J Immunol 186:69056913. https://doi.org/10.4049/jimmunol.1100274

12. Watkins SK, Zhu Z, Riboldi E, Shafer-Weaver KA, Stagliano KE, Sklavos MM, Ambs S, Yagita H, Hurwitz AA (2011) FOXO3 programs tumor-associated DCs to become tolerogenic in human and murine prostate cancer. J Clin Invest 121:1361-1372. https:// doi.org/10.1172/JCI44325

13. Fukuyama T, Ichiki Y, Yamada S et al (2007) Cytokine production of lung cancer cell lines: Correlation between their production and the inflammatory/immunological responses both in vivo and in vitro. Cancer Sci 98:1048-1054. https://doi.org/10.111 1/j.1349-7006.2007.00507.x

14. Hasegawa Y, Takanashi S, Kanehira Y, Tsushima T, Imai T, Okumura K (2001) Transforming growth factor-beta1 level correlates with angiogenesis, tumor progression, and prognosis in patients with nonsmall cell lung carcinoma. Cancer 91:964-971

15. Liu VC, Wong LY, Jang T et al (2007) Tumor evasion of the immune system by converting CD4 + CD25- T cells into CD4 
$+\mathrm{CD} 25+\mathrm{T}$ regulatory cells: role of tumor-derived TGF-beta. J Immunol 178:2883-2892

16. Chen W, Lu Y, Chen G, Huang S (2013) Molecular evidence of cryptotanshinone for treatment and prevention of human cancer. Anticancer Agents Med Chem 13:979-987

17. Takiura K (1941) Study on components of Danshen: the structure of cryptotanshinone. J Pharm Soc JPN 61:482-490

18. Inouye Y, Kakisawa H (1969) Total syntheses of Tanshinone-I, Tanshinone-II and crytotanshinone. Bull Chem Soc 42:3318-3323

19. Yang D, Chen Q, Su SB et al (2008) Eosinophil-derived neurotoxin acts as an alarmin to activate the TLR2-MyD88 signal pathway in dendritic cells and enhances Th2 immune responses. J Exp Med 205:79-90

20. Nie Y, Yang, Trivett A, Han Z, Xin H, Chen X, Oppenheim JJ (2017) Development of a curative therapeutic vaccine (TheraVac) for the treatment of large established tumors. Sci Rep 7:14186. https://doi.org/10.1038/s41598-017-14655-8

21. Zou W, Chen L (2008) Inhibitory B7-family molecules in the tumour microenvironment. Nat Rev Immunol 8:467-477. https:// doi.org/10.1038/nri2326

22. Zhang Y, Huang S, Gong D, Qin Y, Shen Q (2010) Programmed death-1 upregulation is correlated with dysfunction of tumorinfiltrating CD8 + T lymphocytes in human non-small cell lung cancer. Cell Mol Immunol 7:389-395. https://doi.org/10.1038/ cmi.2010.28

23. Trinchieri G (2003) Interleukin-12 and the regulation of innate resistance and adaptive immunity. Nat Rev Immunol 3:133-146

24. Kapsenberg ML (2003) Dendritic-cell control of pathogen-driven T-cell polarization. Nat Rev Immunol 3:984-993. https://doi. org/10.1038/nri1246

25. Banchereau J, Steinman RM (1998) Dendritic cells and the control of immunity. Nature 392:245-251

26. Liu YJ (2001) Dendritic cell subsets and lineages, and their functions in innate and adaptive immunity. Cell 106:259-262

27. Taylor WR, Stark GR (2001) Regulation of the G2/M transition by $\mathrm{p} 53$. Oncogene 20:1803-1815. https://doi.org/10.1038/ sj.onc. 1204252

28. Somasundaram K (2000) Tumor suppressor p53: regulation and function. Front Biosci 5:D424-D437

29. Harper JW, Adami GR, Wei N, Keyomarsi K, Elledge SJ (1993) The p21 Cdk-interacting protein Cip1 is a potent inhibitor of G1 cyclin-dependent kinases. Cell 75:805-816

30. Harper JW, Elledge SJ, Keyomarsi K et al (1995) Inhibition of cyclin-dependent kinases by p21. Mol Biol Cell 6:387-400

31. Innocente SA, Abrahamson JL, Cogswell JP, Lee JM (1999) p53 regulates a G2 checkpoint through cyclin B1. Proc Natl Acad Sci USA 96:2147-2152

32. Chen L, Wang HJ, Xie W, Yao Y, Zhang YS, Wang H (2014) Cryptotanshinone inhibits lung tumorigenesis and induces apoptosis in cancer cells in vitro and in vivo. Mol Med Rep 9:24472452. https://doi.org/10.3892/mmr.2014.2093

33. Hao W, Zhang X, Zhao W, Zhu H, Liu ZY, Lu J, Chen X (2016) Cryptotanshinone induces pro-death autophagy through JNK signaling mediated by reactive oxygen species generation in lung cancer cells. Anticancer Agents Med Chem 16:593-600

34. Dong H, Strome SE, Salomao DR et al (2002) Tumor-associated B7-H1 promotes T-cell apoptosis: a potential mechanism of immune evasion. Nat Med 8:793-800. https://doi.org/10.1038/ $\mathrm{nm} 730$

35. Iwai $\mathrm{Y}$, Ishida $\mathrm{M}$, Tanaka $\mathrm{Y}$, Okazaki $\mathrm{T}$, Honjo $\mathrm{T}$, Minato $\mathrm{N}$ (2002) Involvement of PD-L1 on tumor cells in the escape from host immune system and tumor immunotherapy by PD-L1 blockade. Proc Natl Acad Sci USA 99:12293-12297. https://doi. org/10.1073/pnas.192461099

36. Shin DS, Kim HN, Shin KD, Yoon YJ, Kim SJ, Han DC, Kwon BM (2009) Cryptotanshinone inhibits constitutive signal transducer and activator of transcription 3 function through blocking the dimerization in DU145 prostate cancer cells. Cancer Res 69:193-202. https://doi.org/10.1158/0008-5472.CAN-08-2575

37. Zhang Y, Won SH, Jiang C et al (2012) Tanshinones from Chinese medicinal herb Danshen (Salvia miltiorrhiza Bunge) suppress prostate cancer growth and androgen receptor signaling. Pharm Res 29:1595-1608. https://doi.org/10.1007/s11095-012-0670-3

38. Xu D, Lin TH, Li S, Da J, Wen XQ, Ding J, Chang C, Yeh S (2012) Cryptotanshinone suppresses androgen receptor-mediated growth in androgen dependent and castration resistant prostate cancer cells. Cancer Lett 316:11-22. https://doi.org/10.1016/j. canlet.2011.10.006

39. Chen W, Luo Y, Liu L et al (2010) Cryptotanshinone inhibits cancer cell proliferation by suppressing Mammalian target of rapamycin-mediated cyclin D1 expression and $\mathrm{Rb}$ phosphorylation. Cancer Prev Res (Phila) 3:1015-1025. https://doi. org/10.1158/1940-6207.CAPR-10-0020

40. Ge Y, Cheng R, Zhou Y et al (2012) Cryptotanshinone induces cell cycle arrest and apoptosis of multidrug resistant human chronic myeloid leukemia cells by inhibiting the activity of eukaryotic initiation factor 4E. Mol Cell Biochem 368:17-25. https:// doi.org/10.1007/s11010-012-1338-3

41. Li S, Wang H, Hong L, Liu W, Huang F, Wang J, Wang P, Zhang X, Zhou J (2015) Cryptotanshinone inhibits breast cancer cell growth by suppressing estrogen receptor signaling. Cancer Biol Ther 16:176-184. https://doi.org/10.4161/15384047.2014.96296 0

42. Ge Y, Yang B, Chen Z, Cheng R (2015) Cryptotanshinone suppresses the proliferation and induces the apoptosis of pancreatic cancer cells via the STAT3 signaling pathway. Mol Med Rep 12:7782-7788. https://doi.org/10.3892/mmr.2015.4379

43. Li W, Saud SM, Young MR, Colburn NH, Hua B (2015) Cryptotanshinone, a Stat 3 inhibitor, suppresses colorectal cancer proliferation and growth in vitro. Mol Cell Biochem 406:63-73. https ://doi.org/10.1007/s11010-015-2424-0

44. Zhang Y, Cabarcas SM, Zheng JI, Sun L, Mathews LA, Zhang X, Lin H, Farrar WL (2016) Cryptotanshinone targets tumor-initiating cells through down-regulation of stemness genes expression. Oncol Lett 11:3803-3812. https://doi.org/10.3892/ol.2016.4444

Publisher's Note Springer Nature remains neutral with regard to jurisdictional claims in published maps and institutional affiliations. 